\title{
O QUE É POSITIVISMO, AFINAL? E QUAL POSITIVISMO?
}

\author{
WHAT IS POSITIVISM, AFTER ALL? AND WHAT POSITIVISM?
}

AL FINAL, ¿QUÉ ES POSITIVISMO? ¿Y CUÁL POSITIVISMO?

\author{
Lenio Luiz Streck ${ }^{1}$
}

Licença CC BY:

Artigo distribuído sob os termos Creative Commons, permite uso e distribuição irrestrita em qualquer meio desde que 0 autor credite a fonte original.

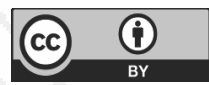

Resumo: Eros Roberto Grau publicou contundente artigo no jornal O Estado de São Paulo, em maio de 2018, "em defesa do positivismo jurídico". O ponto é que positivismo não é "aplicar a letra 'fria' [sic] da lei". Talvez já tenha sido quando, na França, a Escola da Exegese, baseada em Montesquieu, dizia que o juiz era a bouche de la loi. Desde então, o juiz mudou, a lei mudou, a França mudou, o Brasil mudou, o mundo mudou. Logo, mudou o positivismo também. Positivismo é muito mais do que aquilo que foi a sua formulação original: o legalismo. O professor e ex-ministro Eros Roberto Grau acerta no início, quando liga ao positivismo uma ideia de separação entre concepções - talvez, para os positivistas, conceitos —, sejam elas(es) meramente pessoais, subjetivas(os), ou não, de justiça e direito positivo. Essa ideia pode ser vista na clássica formulação de John Austin, pai da jurisprudência analítica.

Palavras-chave: Positivismo; Exegetismo francês; Jurisprudência dos conceitos; Jurisprudência analítica.

1 Doutor em Direito pela UFSC e pós-doutor em Direito pela FDUL. Professor titular do PPG Direito da Universidade do Vale do Rio dos Sinos (Unisinos/ São Leopoldo - RS) e da Universidade Estácio de Sá (UNESA/RJ). Professor Visitante da Universidade Javeriana de Bogotá, da Universidade de Málaga e da Universidade de Lisboa. Professor emérito da Escola da Magistratura do Rio de Janeiro. Membro catedrático da Associação Brasileira de Direito Constitucional - ABDConst. Presidente de honra do Instituto de Hermenêutica Jurídica (IHJ). Coordenador do Dasein - Núcleo de Estudos Hermenêuticos. Advogado. Ex-Procurador de Justiça do Estado do Rio Grande do Sul. E-mail: lenio@unisinos.br. 
Abstract: Eros Roberto Grau published a powerful article in the newspaper O Estado de São Paulo in May 2018, entitled "em defesa do positivismo jurídico" (in defense of legal positivism). The point is that positivism is not about "applying the 'cold' letter [sic] of the law." Perhaps it was already when, in France, the School of Exegesis, based in Montesquieu, said that the judge was a bouche de la loi. Since then, the judge has changed, the law has changed, France has changed, Brazil has changed, the world has changed. Positivism has also changed. Positivism is much more than what it was in its original formulation: legalism. Professor Eros Grau agrees at the beginning, when he connects positivism with an idea of the separation of conceptions, whether they are merely personal, subjective, or not, pertaining to justice and positive law. This idea can be seen in the classic formulation of John Austin, the father of analytical jurisprudence.

Keywords: Positivism; French exegetism; Jurisprudence of concepts; Analytical jurisprudence.

Resumen: Eros Roberto Grau publicó un contundente artículo en el periódico O Estado de São Paulo, en mayo de 2018, "en defensa del positivismo jurídico". El punto es que positivismo no es "aplicar la letra 'fría' [sic] de la ley". Tal vez ya ha sido cuando, en Francia, la Escuela de la Exégesis, basada en Montesquieu, decía que el juez era la bouche de la loi. Desde entonces, el juez cambió, la ley cambió, Francia cambió, Brasil cambió, el mundo cambió. Luego, cambió el positivismo también. Positivismo es mucho más que su fórmula original: el legalismo. El profesor y exministro Eros Roberto Grau acierta al comienzo, cuando relaciona al positivismo una idea de separación entre concepciones - tal vez, para los positivistas, conceptos —, sean ellas(os) meramente personales, subjetivas(os), o no, de justicia y derecho positivo. Esta idea puede ser vista en la clásica formulación de John Austin, padre de la jurisprudencia analítica.

Palabras-clave: Positivismo; Exegetismo francés; Jurisprudencia de los conceptos; Jurisprudencia analítica.

\section{INTRODUÇÃO}

O Professor e ex-Ministro do Supremo Tribunal Federal, Eros Roberto Grau, publicou contundente artigo no jornal O Estado de São Paulo, ${ }^{2}$ em maio de 2018, "em defesa do positivismo jurídico". Basicamente as razões pelas quais se declara um positivista foram as de que "os juízes interpretam/aplicam a lei, não fazem justiça" e que "[o] que caracteriza o Direito moderno é a objetividade da lei, a ética da legalidade".

Diz também, repetindo o que já escrevera no livro Porque Tenho Medo dos Juízes ${ }^{3}$, que tem medo dos juízes, "em especial dos juízes dos nossos tribunais",

$\overline{2}$ O texto em questão foi reproduzido, na íntegra, pelo portal Consultor Jurídico. GRAU, Eros. Juízes interpretam e aplicam a Constituição e as leis, não fazem justiça. Revista Eletrônica Consultor Jurídico, 14 de maio 2018. Disponível em: <https://www.conjur.com.br/2018-mai-14/eros-grau-juizes-aplicam-direito-nao-fazem-justica>. Acesso em: 24 de maio 2018.

3 GRAU, Eros Roberto. Por Que Tenho Medo Dos Juízes. 8 ed. São Paulo: Malheiros, 2017. 
que, segundo ele, insistiriam "em substituir o controle de constitucionalidade por controles de outra espécie, quais os da proporcionalidade e razoabilidade das leis e da ponderação entre princípios".

Ressalvas feitas a algumas questões terminológicas, que se dão em razão de operarmos a partir de paradigmas diferentes, perceberão uma série de similaridades entre o discurso de Eros Grau e o meu. Isso não é por acaso. Eros Grau tem minha admiração, e, mais do que isso, endosso muitas de suas críticas.

Como ele, também sou um defensor da legalidade; como o ex-ministro, também chego, por vezes, a ter medo dos juízes - especialmente dos nossos juízes. Penso que ele acerta sobremaneira ao criticar a (suposta) "ponderação" entre princípios que vemos na práxis brasileira cotidianamente (que, ressalto, da forma como é feita por aqui, é um verdadeiro crime com a teoria alexyana..... ${ }^{4}$

Como Eros Grau, identifico (e venho falando nisso há anos, no que chamo de diferença ontológica) ${ }^{5}$ que entre texto e norma há uma diferença, e não uma cisão.

Suas críticas - repito, porque se faz necessário: ressalvadas algumas de suas terminologias - são acertadas. O direito brasileiro já de há muito demonstra uma série de problemas muito graves. Em nome de uma "justiça" abstrata, juízes afastam, à própria escolha, a lei democraticamente aprovada no Parlamento. A partir de recepções malfeitas de teorias estrangeiras, confere-se um verniz jurídico a decisões que se baseiam em nada mais que a vontade do julgador. Odes por segurança jurídica, por parte de personalidades como Eros Grau, são, mais do que bem-vindas, necessárias.

4 Os princípios são, para Alexy, mandados de otimização e possuem, por isso, uma estrutura alargada de deverser. Essa estrutura, que é dada prima facie, tenciona os princípios, fazendo-os colidir. A valoração é um momento subsequente - ou seja, posterior à colisão - que incorpora o procedimento da ponderação. O mais paradoxal nesse sincretismo teórico é que Alexy elabora sua teoria exatamente para "racionalizar" a ponderação de valores, ao passo que, no Brasil, os pressupostos formais - racionalizadores - são integralmente desconsiderados na maioria dos casos. Ademais - como se não bastasse —, na importação brasileira de Alexy, alguns juristas, como Luís Roberto Barroso e Ana Paula de Barcellos, propõem que, além da ponderação de princípios, deve existir também uma ponderação entre regras; tese esta repetida, sob outro fundamento, por Humberto Ávila. Sobre o ponto, ver o verbete ponderação, de meu Dicionário de Hermenêutica; Ponderação e Arbitrariedade, de Fausto de Morais; e Direitos Fundamentais e Teoria Discursiva, de Rafael Giorgio Dalla Barba. Cf. STRECK, Lenio Luiz. Dicionário de Hermenêutica: quarenta temas fundamentais da Teoria do Direito à luz da Crítica Hermenêutica do Direito. Belo Horizonte: Casa do Direito, 2017; DALLA BARBA, Rafael Giorgio. Direitos Fundamentais e Teoria Discursiva: dos pressupostos teóricos às limitações práticas. Salvador: Juspodivm, 2018; DE MORAIS, Fausto Santos. Ponderação e Arbitrariedade: a inadequada recepção de Alexy pelo STF. Salvador: Juspodivm, 2016.

5 Sobre o ponto, ver o verbete diferença ontológica, de meu Dicionário de Hermenêutica. Cf. STRECK, Lenio Luiz. Dicionário de Hermenêutica: quarenta temas fundamentais da Teoria do Direito à luz da Crítica Hermenêutica do Direito. Belo Horizonte: Casa do Direito, 2017. 


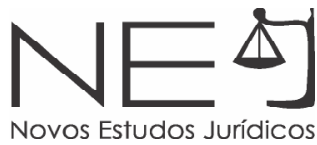

Há, porém, um problema: meu caminho ao lado de Eros Roberto Grau vai até um determinado ponto. Acompanho o ex-ministro, mas somente até o momento em que chegamos a certa altura da estrada. Chega uma hora em que tomamos rumos diferentes. Ao identificarmos os mesmos problemas, Eros Grau diz: "sou um positivista!". É aí que nos separamos. Uma vez mais, aqueles que são minimamente familiarizados com a Crítica Hermenêutica do Direito ${ }^{6}$ já bem sabem que sou um grande crítico do positivismo jurídico.

Mas há, em minhas críticas à conclusão a que chega o ex-ministro, outro ponto fundamental: a "solução" que ele encontra está baseada em uma premissa que, ainda que comece certa, termina fundamentalmente errada. Como vimos, Eros Grau, a partir de seus (mais do que justificados) receios com relação ao rumo que tem tomado o direito brasileiro, coloca-se "em defesa do positivismo jurídico"; o problema é que o positivismo que o ex-ministro defende já não existe mais. Desde o século XIX. É o que vou demonstrar aqui. Baseado em critérios.

\section{DE COMO AS DIFERENTES VERSÕES DO POSITIVISMO SÃO CONFUNDIDAS E MAL COMPREENDIDAS}

Isto deve ser dito: o artigo assinado por Eros Grau não é o único baseado em uma compreensão equivocada acerca do que é o positivismo jurídico. $\mathrm{Na}$ verdade, assim falando, Eros Grau representa o pensamento médio da comunidade jurídica brasileira. Ou seja, é somente (mais) uma manifestação de uma doutrina que falhou epistemicamente ao (tentar) responder o que é isto - o positivismo?

De todo modo, o ensaio publicado no Estadão serve como um bom ponto de partida para que seja possível, uma vez mais, desmi(s)tificar a vasta série de equívocos quando o assunto é esse. No Brasil, nas salas de aula, repete-se o mantra: "positivismo

6 A Crítica Hermenêutica do Direito por mim fundada constitui matriz teórica que, sob os aportes da filosofia (em especial, da filosofia hermenêutica de Heidegger e da hermenêutica filosófica de Gadamer), possibilita a análise crítica do fenômeno jurídico. Esse movimento também sofre influências de Warat no tocante à sua crítica ao senso comum téorico, incorporando ainda a noção de coerência e integridade de Dworkin. Trata-se, portanto, de uma matriz teórica para o direito com fundamentos filosóficos e de teoria do direito. Sob o aspecto metodológico, desenvolve-se sob o prisma do método fenomenológico hermenêutico. O ponto central da adoção desta metodologia consiste na ruptura com as tradicionais estruturas metodológicas da modernidade, que indicam a ideia de certeza e segurança próprias da matematicidade do pensamento moderno. Em contraposição a isso, o método fenomenológico hermenêutico implica um modo de filosofar, concebendo os caminhos metodológicos como precários e provisórios, ou seja, elementos dos quais não se possui total apreensão e domínio. Em poucas palavras: revolve-se o chão linguístico em que está assentada a tradição, reconstruindo a história institucional do fenômeno. 
é aplicar a 'letra fria' [sic] da lei!". Por confundirem positivismo com legalidade, já fui, muitas vezes, chamado de positivista. Até mesmo por Eros Grau, quem disse, em seminário em Coimbra, que eu queria proibir os juízes de interpretar.

O ponto é que positivismo não é "aplicar a letra 'fria' [sic] da lei". Talvez já tenha sido quando, na França, a Escola da Exegese, baseada em Montesquieu, dizia que o juiz era a bouche de la loi ("a boca da lei"). Lembremos, contudo, que "a lei" ainda era a lei do Code Napoléon. Desde então, o juiz mudou, a lei mudou, a França mudou, o Brasil mudou, o mundo mudou. Por óbvio, mudou o positivismo também - mas, ao que parece, ainda insistem que sou um positivista por dizer que o texto legal importa, ${ }^{8}$ e talvez seja pelo mesmo motivo que ainda ressoe, nas salas de aula, que Kelsen - sobre quem falarei com mais vagar no tópico subsequente - era um exegeta. Positivismo é muito mais do que aquilo que foi a sua formulação original: o legalismo (seja ele manifestado através do exegetismo francês, da jurisprudência dos conceitos na Alemanha, ou através da jurisprudência analítica inglesa - inaugurada, em certa medida, por Jeremy Bentham, em sua expository jurisprudence, que, somada ao todo, levava à campanha pela codificação do Direito em substituição ao common law). ${ }^{9}{ }^{10}$

O professor e ex-ministro Eros Roberto Grau acerta no início, quando liga ao positivismo uma ideia de separação entre concepções - talvez, para os

7 Sobre positivismo e sua complexidade, sugiro a leitura de professores brasileiros como: TORRANO, Bruno. A "aliança estratégica" entre positivismo jurídico e hermenêutica de Lenio Streck. Consultor Jurídico, São Paulo, março de 2016. Disponível em: <https://www.conjur.com.br/2016-mar-23/alianca-estrategica-entre-positivismohermeneutica-streck>. Acesso em 13 jul. 18; COELHO, André. Raz: Direito, autoridade e positivismo exclusivo. Filósofo Grego, Pará, novembro de 2012. Disponível em: <http://aquitemfilosofiasim.blogspot.com/2012/11/razdireito-autoridade-e-positivismo.html>. Acesso em 13 jul. 18; COELHO, André. Raz: Razões de primeira ordem, de segunda ordem e autoridade. Filósofo Grego, Pará, novembro de 2012. Disponível em: <http://aquitemfilosofiasim. blogspot.com/search?q=joseph+raz>. Acesso em 13 jul. 18; COELHO, André. "Legality", de Scott J. Shapiro: uma introdução. Filósofo Grego, Pará, fevereiro de 2016. Disponível em: <http://aquitemfilosofiasim.blogspot. com/2016/02/legality-de-scott-j-shapiro-uma.html>. Acesso em 13 jul. 18; BUSTAMANTE, Thomas. A breve história do positivismo descritivo. O que resta do positivismo jurídico depois de H. L. A. Hart? Novos Estudos Jurídicos (On-line), v. 20, p. 307-327, 2015.

8 Vejam: De "o texto legal importa" não se segue que eu acredite nas falácias já superadas pelo próprio positivismo de que a aplicação do Direito como deve ser implica em um textualismo raso, ingênuo, segundo o qual basta "aplicar o que está escrito" (como se isso (i) fosse possível e (ii) significasse alguma coisa).

9 Falei sobre isso nas notas introdutórias que acrescentei à última edição de meu Verdade e Consenso. Cf. STRECK, Lenio Luiz. Verdade e Consenso: Constituição, Hermenêutica e Teorias Discursivas. 6. ed., revista e ampliada. São Paulo: Saraiva, 2017.

10 Para uma desmi(s)tificação da obra de Jeremy Bentham, ver artigo que publiquei na Revista Brasileira de Direito Processual, em coautoria com Igor Raatz e Gilberto Morbach. Cf. STRECK, Lenio Luiz; RAATZ, Igor; MORBACH, Gilberto. Desmistificando o positivismo de Jeremy Bentham: sua codificação utilitarista e a rejeição ao stare decisis como autorização para errar por último. Revista Brasileira de Direito Processual - RBDPro, ano 25, n. 99, jul./ set. 2017, pp. 221-242. 


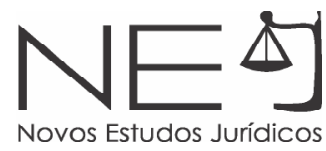

positivistas, conceitos —, sejam elas(es) meramente pessoais, subjetivas(os), ou não, de justiça e direito positivo. Essa ideia pode ser vista na clássica formulação de John Austin, pai da (já brevemente mencionada) jurisprudência analítica (hoje conhecida como positivismo clássico inglês, já que, ainda que, à época, não levasse o nome de positivismo, o reconhecimento do germe do fenômeno nessa escola é unânime na doutrina). ${ }^{11}$ Para Austin, muito diretamente,

[...] a existência do Direito é uma coisa; seus méritos ou deméritos, outra. Existir é uma questão; estar de acordo a um determinado padrão é outra. Uma leique de fato existeéuma lei, ainda que eventualmente desgostemos dela, ou venha de um texto que aprovamos ou desaprovamos. ${ }^{12}$

Aqui, fica muito clara a origem das grandes teses positivistas: (i) a tese da separabilidade entre Direito e moral e (ii) a tese das fontes sociais, ${ }^{13}$ que são as únicas fontes responsáveis pelo Direito. Veja-se que Hart - provavelmente, o maior nome do positivismo jurídico anglo-saxão, de quem também falarei com mais vagar a seguir — dá uma definição muito parecida: diz que o positivismo "designa a afirmação simples de que não é necessariamente verdade que as leis reproduzam certas exigências da moral ou a satisfaçam". ${ }^{14}$

O problema é que, daí em diante, Eros Grau esquece a grande pretensão que dominou as teorias positivistas a partir de Austin. Ela é nada mais que a tentativa de desenvolver teorias capazes de, tão somente, descrever o Direito, de forma moralmente neutra.

A tradição dominante do positivismo jurídico nunca disse que o juiz tem um dever de aplicar o texto legal. Mais: a tradição positivista dominante jamais disse nada sobre a atuação do juiz per se. Característica típica do juspositivismo é, justamente, não se preocupar com a decisão judicial. É essa minha divergência

11 Apenas para um esclarecimento terminológico - sou um hermeneuta; palavras importam: disso não se segue, necessariamente, que unanimidade, consenso, signifiquem verdade.

12 Tradução livre para "[t]he existence of law is one thing; its merit or demerit is another. Whether it be or not is one enquiry; whether it be or be not conformable to an assumed standard, is a different enquiry. A law, which actually exists, is a law, though we happen to dislike it, or though it vary from the text, by which we regulate our approbation and disapprobation". Em AUSTIN, John. The Province of Jurisprudence Determined. Edited by Wilfrid E. Rumble. Cambridge: Cambridge University Press, 2001 [1832], p. 157.

13 Naquilo que Ronald Dworkin (bem) chama - e eu acompanho - de tese do pedigree. Para essa e outras belas críticas do positivismo, ver O Modelo de Regras I. Cf. DWORKIN, Ronald. Levando os Direitos a Sério. 1. ed. Tradução de Nelson Boeira. São Paulo: Martins Fontes, 2002, pp. 23-72.

14 HART, H. L. A. O Conceito de Direito. Pós-escrito organizado por Penelope A. Bulloch e Joseph Raz; tradução de Antônio de Oliveira Sette-Câmara. São Paulo: WMF Martins Fontes, 2012, p. 240. 
com o positivismo, e é esse o equívoco de Eros Grau. Como defender que os juízes respeitem a lei invocando uma teoria cuja tradição dominante nada tem a dizer sobre a forma como os juízes devem se comportar?

Veja-se, ainda, que é muito pelo contrário. Explico: retomando, depois de Austin, no século XIX, o grande nome do positivismo é H. L. A. Hart. Já na década de 1960, de forma muito sofisticada, ${ }^{15}$ Hart vai modernizar, em sua obra O Conceito de Direito - a partir de paradigmas inaugurados por Ludwig Wittgenstein, em Investigações Filosóficas - o conceito que Austin havia formulado: aquele segundo o qual o Direito era, simplesmente, o comando de um soberano. ${ }^{16}$

Para Hart, o Direito era, em verdade, uma união entre regras primárias (i.e. regras diretas, que regulam as condutas) e regras secundárias (regras acerca da modificação e funcionamento das regras primárias), constituindo uma prática social originada a partir daquilo que o autor denominou de regra de reconhecimento - uma convenção entre os funcionários do sistema, responsáveis pela aplicação do Direito, a partir da qual estes aceitam e aplicam os padrões e os critérios que pautam o funcionamento do sistema jurídico. ${ }^{17}$

Não é o propósito deste texto pormenorizar a teoria hartiana. Contudo, é importante que tenhamos em mente ao menos essas brevíssimas noções para que entendamos por que o positivismo, como ele é efetivamente é o exato oposto do que dá a entender o artigo de Eros Grau. Hart - que deixa muito claro não se preocupar em dizer como o Direito deve ser, ao mencionar, ao início de sua já mencionada magnum opus, que pretende ${ }^{18}$ fazer uma espécie de "sociologia

15 Isto tem de ser dito: minhas divergências e ressalvas ao fenômeno não significam que eu não respeite os teóricos positivistas, suas complexidades e, sobretudo, seu importantíssimo legado; muito pelo contrário. Tenho profundo respeito por autores como Kelsen, Hart e até mesmo os mais contemporâneos, como Raz, Marmor e Shapiro.

16 Era assim que, desde Hobbes e Bentham, Austin conceituava o Direito - e, consequentemente, diferenciava o comando jurídico de outras espécies, como pressões exercidas pela moralidade pública, comandos divinos (Austin, diga-se, era um cristão), etc.: era direito válido aquilo que fosse um comando do soberano e implicasse uma sanção na hipótese de descumprimento.

17 No positivismo de Austin e Hart, além de uma série de outras versões, são explicitadas com mais vagar no verbete positivismo jurídico, de meu Dicionário de Hermenêutica. Cf. STRECK, Lenio Luiz. Dicionário de Hermenêutica: quarenta temas fundamentais da Teoria do Direito à luz da Crítica Hermenêutica do Direito. Belo Horizonte: Casa do Direito, 2017.

18 E digo "pretende" porque, para mim - e para quem opera a partir de um paradigma hermenêutico —, descrições moralmente neutras são impossíveis. Não subscrevo à tese humeniana de que há uma dicotomia entre fato e valor. Para explicar, peço licença para tomar emprestado o belo argumento de Alasdair Maclntyre (filósofo moral que defende um retorno a Aristóteles e à ética das virtudes). Vejamos: das premissas aparentemente descritivas que dispõem, por exemplo, que (i) "o relógio não marca as horas corretamente" e (ii) "o fazendeiro teve um índice de produção maior do que todos os outros" seguem-se, logicamente, as premissas "o relógio é ruim" e "o fazendeiro é bom". Porque, nas palavras de Maclntyre, "o conceito de relógio não pode ser definido independentemente do conceito de um bom relógio e o conceito de fazendeiro independentemente do bom fazendeiro". MACINTYRE, Alasdair. After Virtue: A Study in Moral Theory. 3. ed. Notre Dame: University of Notre Dame Press, 2007, p. 57-58. 


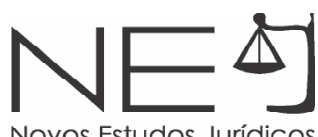

descritiva" do Direito - baseia sua (tentativa de) descrição acerca do que é o Direito em (i) convenções e, desde sua herança na filosofia da linguagem ordinária, (ii) na ideia de que os textos jurídicos denotam, em algum momento, um grau de textura aberta. As conclusões são óbvias: convenções esgotam-se, e texturas abertas podem gerar dúvidas quando da aplicação. Hart e os positivistas não são ingênuos; longe disso. São teóricos sérios, e, por isso, não negam aquilo que é inegável. Contudo, apostam em uma solução que não me parece adequada: a discricionariedade. As considerações de Hart sobre a textura aberta são elucidativas:

[...] não apenas no terreno das normas, mas em todos os caminhos da existência, há um limite inerente à natureza da linguagem, para a orientação que a linguagem geral pode oferecer. ${ }^{19}$

Para Hart, qualquer que seja a estratégia escolhida para a transmissão de padrões de comportamento - leis, precedentes, etc. - jamais será completa, porque

[...] esses padrões, por muito facilmente que funcionem na grande massa de casos comuns se mostrarão imprecisos em algum ponto, quando sua aplicação for posta em dúvida; terão o que se tem chamado de textura aberta. ${ }^{20}$

Em outras palavras, o positivismo, ao reconhecer que é impossível - quando se fala em Direito - conceber um código, uma legislação, um sistema completo, infinito, aceita que, quando a convenção termina, o juiz decida com base em seu juízo discricionário. Dworkin, em suas críticas, resumiu bem: para o positivista, "quando não há regra clara disponível, deve-se usar o poder discricionário pra julgar". ${ }^{21}$ Ora, esse resultado nem poderia ser diferente: o positivista não tem pretensões de dizer como o Direito deve ser aplicado. A discricionariedade tornase, pois, nada mais que um resultado natural.

Por que essa digressão? Para que fique muito evidente o quanto está equivocado o artigo de Eros Grau — que, como disse, é apenas uma manifestação

19 HART, H. L. A. O Conceito de Direito. Pós-escrito organizado por Penelope A. Bulloch e Joseph Raz; tradução de Antônio de Oliveira Sette-Câmara. São Paulo: WMF Martins Fontes, 2012, p. 164.

20 HART, H. L. A. O Conceito de Direito. Pós-escrito organizado por Penelope A. Bulloch e Joseph Raz; tradução de Antônio de Oliveira Sette-Câmara. São Paulo: WMF Martins Fontes, 2012, p. 166.

21 DWORKIN, Ronald. Levando os Direitos a Sério. 1. ed. Tradução de Nelson Boeira. São Paulo: Martins Fontes, 2002, p. 55. 
de um senso comum teórico - ao defender a legalidade, a aplicação e o respeito à lei, com base em uma teoria que (i) não está preocupada em dizer como deve funcionar a aplicação do Direito e, mais, (ii) aceita a tese da discricionariedade. É o exato oposto do que parece defender o artigo do ex-ministro.

\section{(AINDA) KELSEN (DE NOVO)}

Há, ainda, outro trecho do texto de Eros Grau que salta aos olhos: diz que "[a] justiça absoluta - aprendi esta lição em Kelsen - é um ideal irracional; a justiça absoluta só pode emanar de uma autoridade transcendente, só pode emanar de Deus".

Pois bem, não compartilho do relativismo de Eros Grau (e de Kelsen). Penso que, além de equivocado, o não cognitivismo ético representa um grande risco de que aceitemos que tudo é relativo (para não mencionar o paradoxo: quem diz que não há verdades tem, ao mesmo tempo, por óbvio, a pretensão de estar dizendo a verdade). De todo modo, ao menos nisto o ex-ministro acerta: Kelsen era mesmo um relativista no âmbito da metaética. ${ }^{22}$

Contudo, não deixa de ser curioso perceber que uma das inspirações de Eros Grau, em texto (supostamente) em defesa do "positivismo", para defender uma aplicação adequada do Direito seja logo Kelsen. Porque a ideia de que Kelsen defendia que os juízes deviam aplicar a lei é tão difundida quanto equivocada. Kelsen não separou Direito e moral; Kelsen jamais preconizou aplicação legalista do Direito.

Dizer o contrário é mal compreender o título da obra mais lida de Kelsen quando o assunto é este: Teoria Pura do Direito. É a teoria que é pura, não o Direito; ${ }^{23}$ como (muito) bem dizia o saudoso Luis Alberto Warat, que compreendeu Kelsen como poucos, a pureza está no olhar, e não no objeto olhado. Como bem ressalta Leonel Severo Rocha, que, com Warat, sabe dizer que, em Kelsen, "[o] Direito é a linguagem-objeto, a ciência do Direito é a metalinguagem: dois planos distintos e incomunicáveis". ${ }^{24}$

22 Sobre o ponto - tanto em Kelsen quanto no Direito lato sensu —, ver o belíssimo Metaética e a Fundamentação do Direito, de Arthur Ferreira Neto. Cf. FERREIRA NETO, Arthur Maria. Metaética e a Fundamentação do Direito. Porto Alegre: Elegantia Juris, 2015.

23 Ver o verbete a pureza do Direito kelseniana, em meu Dicionário de Hermenêutica. Cf. STRECK, Lenio Luiz. Dicionário de Hermenêutica: quarenta temas fundamentais da Teoria do Direito à luz da Crítica Hermenêutica do Direito. Belo Horizonte: Casa do Direito, 2017.

24 ROCHA, Leonel Severo. Epistemologia Jurídica e Democracia. 2. ed. São Leopoldo: Unisinos, 2003, p. 72. 


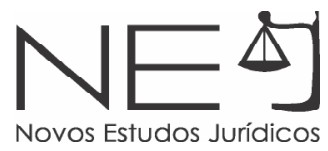

Ou seja: em Kelsen, há uma cisão não entre Direito e Moral; pelo contrário. Há, sim, uma cisão entre Direito e Ciência do Direito. Para Kelsen, o Direito, linguagem objeto, deve ser descrito pela Ciência do Direto, metalinguagem. No primeiro, as normas, que exsurgem de um ato de vontade (do legislador na elaboração das leis, do juiz na interpretação e na sentença), carregam, em si, um espaço de mobilidade sob o qual se movimenta o intérprete, em razão dos problemas semânticos que se verificam na aplicação de um signo linguístico. Agora, no segundo, a interpretação é ato de conhecimento: na descrição do Direito, em metalinguagem, a Ciência do Direito produz proposições inter-relacionáveis, de maneira lógico-formal. Daí fica muito claro que Kelsen não só nunca separou Direito e moral como, inclusive, entendia completamente o contrário; em Kelsen, o Direito é política jurídica, envolve moral, subjetivismos. Isso é muito claro.

Kelsen teve seu célebre debate constitucional com Carl Schmitt no ano de 1933; em 1934 escreve Teoria Pura do Direito. No conhecido Capítulo VIII, Kelsen desenvolve pela primeira vez a questão da interpretação, onde prevê que a norma - que é sempre o sentido objetivo imputado a um ato de vontade - opera sempre de uma determinada "moldura", metáfora esta que representa bem a ideia de limites semânticos do texto. Na segunda versão de Teoria Pura do Direito, porém, lançada em 1960, Kelsen abandona a ideia de moldura, determinando que a norma pode ser produzida ainda que "se situe completamente fora da moldura". Com isso, fica claro que até mesmo Kelsen abandona a ideia de que os limites semânticos do texto servem para impor uma limitação nos tribunais. ${ }^{25}$

\section{CONSIDERAÇÕES FINAIS: DE COMO EROS GRAU ACERTA AO ERRAR, E ERRA AO ACERTAR}

É justamente por subscrever ao relativismo moral que Eros Grau não é capaz de exigir uma correta aplicação a partir de uma interpretação autêntica do Direito. Veja como o ex-ministro é, de fato, em muitas medidas, kelseniano:

[...] Eis, pois, a regra: a decisão jurídica correta a ser tomada em cada caso há de ser aquela que o juiz entende, em sua consciência, que deve (não que pode) tomar. O grave está em que cada caso comporta mais de uma solução correta, nenhuma exata.

25 KELSEN, Hans. Teoria Pura do Direito. Tradução de João Baptista Machado. 8. ed. São Paulo: Editora WMF Martins Fontes, 2009, p. 394. 
Eros Grau diz que há mais de uma resposta correta, e que o julgador deve optar por uma delas recorrendo à sua consciência. Relativismo moral; rejeição à tese de que há, em Direito, uma resposta correta;, juízes decidindo discricionariamente, de acordo com suas próprias consciências. O ex-ministro acerta: nada mais positivista que isso. Mas, ao acertar, erra: porque pretende, baseado nessas premissas, defender uma tese não positivista, que não se sustenta a partir de teses positivistas: a de que os juízes devem aplicar corretamente a Constituição e as leis.

Esse é o paradoxo. O texto acerta ao errar - erra ao apostar no relativismo moral, mas, com isso, acerta ao expor, sem querer, a causa e o problema da discricionariedade positivista - e erra ao acertar - acerta em pedir o fim da "ponderação" (à brasileira) e da sobreposição de concepções pessoais de justiça à lei democraticamente aprovada, mas erra ao ver, nisso, a necessidade de uma defesa do positivismo jurídico.

Numa palavra final: há alguns anos, escrevi um texto com o título que era uma pergunta: "Aplicar a letra da lei é uma atitude positivista?"27. O pano de fundo era uma resposta a uma "acusação" de positivismo que uma importante professora me fizera em uma banca de mestrado, quando eu defendia a aplicação de um dispositivo do Código de Processo Penal. Disse ela: "Você quer a aplicação literal da lei? Então você é um positivista". Veja-se, assim, a complexidade do problema. Por isso, escrevi o Dicionário de Hermenêutica Jurídica ${ }^{28}$, no qual o verbete correspondente ao positivismo é o mais extenso. Tem razão de ser.

\section{REFERÊNCIAS DAS FONTES CITADAS}

AUSTIN, John. The Province of Jurisprudence Determined. Edited by Wilfrid E. Rumble. Cambridge: Cambridge University Press, 2001 [1832].

BUSTAMANTE, Thomas. A breve história do positivismo descritivo. O que resta do positivismo

26 Eu, ao contrário, defendo - como Dworkin - a ideia de que há, em Direito, uma resposta correta. Àquilo que o jusfilósofo norte-americano chama de one right answer dei, no contexto brasileiro, o nome de RAC ("Resposta Adequada à Constituição"). No ponto, ver o verbete Resposta Adequada à Constituição, em meu Dicionário de Hermenêutica. Cf. STRECK, Lenio Luiz. Dicionário de Hermenêutica: quarenta temas fundamentais da Teoria do Direito à luz da Crítica Hermenêutica do Direito. Belo Horizonte: Casa do Direito, 2017.

27 STRECK, Lenio Luiz. Aplicar a "Letra da Lei" é uma atitude positivista?. Novos Estudos Jurídicos (Online), v. 15, p. 158-173, 2010.

28 STRECK, Lenio Luiz. Dicionário de hermenêutica: quarenta temas fundamentais da Teoria do Direito a luz da Crítica Hermenêutica do Direito. Belo Horizonte: Casa do Direito, 2017. 


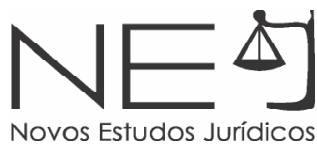

jurídico depois de H. L. A. Hart? Novos Estudos Jurídicos (Online), v. 20, p. 307-327, 2015.

COELHO, André. Raz: Direito, autoridade e positivismo exclusivo. Filósofo Grego, Pará, novembro de 2012. Disponível em: <http://aquitemfilosofiasim.blogspot.com/2012/11/razdireito-autoridade-e-positivismo.html>. Acesso em 13 jul. 18.

Raz: Razões de primeira ordem, de segunda ordem e autoridade. Filósofo Grego, Pará, novembro de 2012. Disponível em: <http://aquitemfilosofiasim.blogspot.com/ search?q=joseph+raz>. Acesso em 13 jul. 18.

. "Legality", de Scott J. Shapiro: uma introdução. Filósofo Grego, Pará, fevereiro de 2016. Disponível em: <http://aquitemfilosofiasim.blogspot.com/2016/02/legality-de-scott-jshapiro-uma.html >. Acesso em 13 jul. 18.

DALLA BARBA, Rafael Giorgio. Direitos Fundamentais e Teoria Discursiva: dos pressupostos teóricos às limitações práticas. Salvador: Juspodivm, 2018.

DE MORAIS, Fausto Santos. Ponderação e Arbitrariedade: a inadequada recepção de Alexy pelo STF. Salvador: Juspodivm, 2016.

DWORKIN, Ronald. Levando os Direitos a Sério. 1. ed. Tradução de Nelson Boeira. São Paulo: Martins Fontes, 2002.

FERREIRA NETO, Arthur Maria. Metaética e a Fundamentação do Direito. Porto Alegre: Elegantia Juris, 2015.

GRAU, Eros. Juízes interpretam e aplicam a Constituição e as leis, não fazem justiça. Revista Eletrônica Consultor Jurídico, 14 de maio 2018. Disponível em: <https://www.conjur.com. br/2018-mai-14/eros-grau-juizes-aplicam-direito-nao-fazem-justica>. Acesso em: 24 de maio 2018.

Por Que Tenho Medo Dos Juízes. 8 ed. São Paulo: Malheiros, 2017.

HART, H. L. A. O Conceito de Direito. Pós-escrito organizado por Penelope A. Bulloch e Joseph Raz; tradução de Antônio de Oliveira Sette-Câmara. São Paulo: WMF Martins Fontes, 2012.

KELSEN, Hans. Teoria Pura do Direito. Tradução de João Baptista Machado. 8. ed. São Paulo: WMF Martins Fontes, 2009.

ACINTYRE, Alasdair. After Virtue: A Study in Moral Theory. 3. ed. Notre Dame: University of Notre Dame Press, 2007, p. 57-58.

STRECK, Lenio Luiz. Dicionário de Hermenêutica: quarenta temas fundamentais da Teoria do Direito à luz da Crítica Hermenêutica do Direito. Belo Horizonte: Casa do Direito, 2017.

Verdade e Consenso: Constituição, Hermenêutica e Teorias Discursivas. 6. ed., revista e ampliada. São Paulo: Saraiva, 2017. 
Aplicar a "Letra da Lei" é uma atitude positivista?. Novos Estudos Jurídicos (Online), v. 15, p. 158-173, 2010.

STRECK, Lenio Luiz; RAATZ, Igor; MORBACH, Gilberto. Desmistificando o positivismo de Jeremy Bentham: sua codificação utilitarista e a rejeição ao stare decisis como autorização para errar por último. Revista Brasileira de Direito Processual - RBDPro, ano 25, n. 99, jul./ set. 2017, pp. 221-242.

TORRANO, Bruno. A "aliança estratégica" entre positivismo jurídico e hermenêutica de Lenio Streck. Consultor Jurídico, São Paulo, março de 2016. Disponível em: < https://www.conjur. com.br/2016-mar-23/alianca-estrategica-entre-positivismo-hermeneutica-streck>. Acesso em 13 jul. 18.

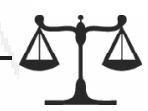

Recebido em: julho/2018

Aprovado em: agosto/2018 